\title{
P-wave indices in patients with pulmonary emphysema: do P-terminal force and interatrial block have confounding effects?
}

This article was published in the following Dove Press journal:

International Journal of COPD

13 May 2013

Number of times this article has been viewed

\section{Lovely Chhabra' \\ Vinod K Chaubey' \\ Chandrasekhar \\ Kothagundla' \\ Rishi Bajaj' \\ Sudesh Kaul' \\ David H Spodick ${ }^{2}$}

'Department of Internal Medicine, ${ }^{2}$ Department of Cardiovascular

Diseases, University of Massachusetts

Medical School, Worcester, MA, USA
Correspondence: Lovely Chhabra, Saint Vincent Hospital, University of Massachusetts Medical School, 285 Plantation Street - \#813,

Worcester, MA 01604, USA

Tel +l 5086675052

Fax + I 8885986647

Email lovids@hotmail.com
Introduction: Pulmonary emphysema causes several electrocardiogram changes, and one of the most common and well known is on the frontal P-wave axis. P-axis verticalization $\left(\mathrm{P}\right.$-axis $\left.>60^{\circ}\right)$ serves as a quasidiagnostic indicator of emphysema. The correlation of $\mathrm{P}$-axis verticalization with the radiological severity of emphysema and severity of chronic obstructive lung function have been previously investigated and well described in the literature. However, the correlation of $\mathrm{P}$-axis verticalization in emphysema with other P-indices like P-terminal force in $\mathrm{V}_{1}$ (Ptf), amplitude of initial positive component of $\mathrm{P}$-waves in $\mathrm{V}_{1}$ (i-PV1), and interatrial block (IAB) have not been well studied. Our current study was undertaken to investigate the effects of emphysema on these P-wave indices in correlation with the verticalization of the P-vector.

Materials and methods: Unselected, routinely recorded electrocardiograms of 170 hospitalized emphysema patients were studied. Significant Ptf (s-Ptf) was considered $\geq 40 \mathrm{~mm}$. $\mathrm{ms}$ and was divided into two types based on the morphology of $\mathrm{P}$-waves in $\mathrm{V}_{1}$ : either a totally negative (-) $\mathrm{P}$ wave in $\mathrm{V}_{1}$ or a biphasic (+/-) $\mathrm{P}$ wave in $\mathrm{V}_{1}$.

Results: s-Ptf correlated better with vertical P-vectors than nonvertical P-vectors $(P=0.03)$. s-Ptf also significantly correlated with IAB $(P=0.001)$; however, IAB and P-vector verticalization did not appear to have any significant correlation $(P=0.23)$. There was a very weak correlation between i-PV1 and frontal P-vector $(r=0.15 ; P=0.047)$; however, no significant correlation was found between i-PV1 and P-amplitude in lead III ( $r=0.07 ; P=0.36)$.

Conclusion: We conclude that increased P-tf in emphysema may be due to downward right atrial position caused by right atrial displacement, and thus the common assumption that increased P-tf implies left atrial enlargement should be made with caution in patients with emphysema. Also, the lack of strong correlation between i-PV1 and P-amplitude in lead III or vertical P-vector may suggest the predominant role of downward right atrial distortion rather than right atrial enlargement in causing vertical P-vector in emphysema.

Keywords: P-terminal force, interatrial block, emphysema, vertical P-vector, P-axis, left atrial enlargement

\section{Introduction}

Pulmonary emphysema is a form of chronic obstructive lung disease characterized by lung hyperinflation, caused by destruction of structures feeding the alveoli, mainly as a result of long-term smoking and rarely due to alpha 1-antitrypsin deficiency. Several electrocardiogram (ECG) changes occur with pulmonary emphysema and may serve as diagnostic markers for the disease. P-wave verticalization is a quasidiagnostic indicator of emphysema, and has long been described in the literature. ${ }^{1-10}$ It also bears a negative correlation with the degree of obstructive lung function and structural severity of the disease. ${ }^{3,6-8}$ Though several other ECG parameters have been well investigated 
in emphysema, its effects on the P-wave indices, namely P-terminal force in $\mathrm{V}_{1}(\mathrm{Ptf})$, amplitude of initial positive component of P-wave in $\mathrm{V}_{1}$ (i-PV1) and interatrial block (IAB), have not been well described by previous studies. Our current investigation was thus undertaken to study the effects of emphysema on these P-wave indices and their correlation with P-vector verticalization.

Ptf is calculated by multiplying the duration of the terminal negative phase of $\mathrm{P}$-wave in $\mathrm{V}_{1}$ (in milliseconds) by its depth in millimeters (Figure 1). Ptf magnitude of $\geq 40 \mathrm{~mm}$.ms, along with the presence of IAB (P-wave duration $>110 \mathrm{~ms}$ ), is considered a highly specific sign for left atrial enlargement. ${ }^{11}$ Since the terminal component of $\mathrm{V}_{1}$ is generated by the left atrium, we determined to measure if emphysema would serve as a confounding factor for Ptf as a criterion for left atrial enlargement, due to its anatomical consequences on the diaphragm and mediastinum. Amplitude of i-PV1 $>1.5 \mathrm{~mm}$ is an established ECG criterion for right atrial enlargement. ${ }^{12}$ We also wanted to see correlation of this finding with the vertical $\mathrm{P}$-vector and $\mathrm{P}$-amplitude in inferior leads in emphysema patients.

\section{Materials and methods}

Unselected, routinely recorded ECGs of 200 hospitalized patients of age $>45$ years and established diagnosis of pulmonary emphysema, based on clinical history, pulmonary function tests, and radiological studies, were reviewed. ECGs with nonsinus and paced rhythms, and poor quality tracings were excluded, leaving 176 good-quality tracings in normal sinus rhythm. Patients $<45$ years of age were excluded because a vertical P-wave axis may be a normal finding in healthy children and young adults. ${ }^{1,3,8-10}$ The ECGs were then analyzed individually by three authors using a handheld $10 \times$ loop magnifier to determine the P-wave indices. Any differences in the individual observations were resolved in a conference consensus.

Frontal $\mathrm{P}$-wave axis/P-vector was calculated by using the P-wave amplitudes in leads I, III and aVL. P-vectors were
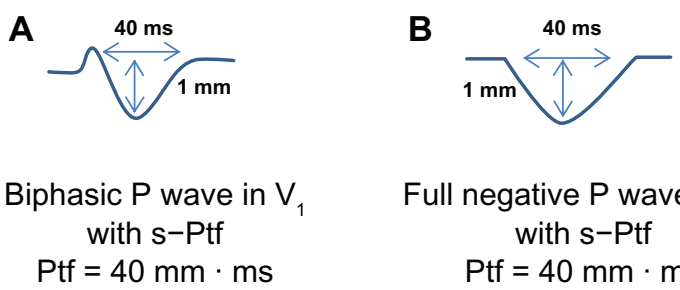
Full negative $P$ wave in $V_{1}$ with $\mathrm{s}-\mathrm{Ptf}$ $\mathrm{Ptf}=40 \mathrm{~mm} \cdot \mathrm{ms}$

considered vertical $\left(>60^{\circ}\right)$ if $\mathrm{P}$-wave amplitude in lead III was greater than in lead I or if net P-wave amplitude in lead aVL was negative. ${ }^{3,8-10}$ Ptf was calculated by multiplying the duration of the terminal negative phase of $\mathrm{P}$-waves in $\mathrm{V}_{1}$ (in milliseconds) and the depth of the terminal negative component of P-waves (in millimeters). A negative Ptf of more than 40 mm.ms (ie, $\mathrm{Ptf} \geq 40 \mathrm{~mm} . \mathrm{ms}$ ) was considered significant (s-Ptf). In our study, we divided the Ptf into two categories, based upon whether it was secondary to a biphasic $\mathrm{P}$-wave in $\mathrm{V}_{1}$ or due to a totally negative $\mathrm{P}$-wave in $\mathrm{V}_{1}$. For calculation of Ptf in biphasic P-waves, the duration and amplitude of terminal negative component of P-waves in $\mathrm{V}_{1}$ were used, but for the calculation of Ptf in fully negative P-waves, the duration and amplitude of the whole negative $\mathrm{P}$-wave in $\mathrm{V}_{1}$ were utilized. IAB was considered to be present if P-wave duration was $\geq 120 \mathrm{~ms}$ for the purposes of our current investigation, in order to achieve good interobserver reproducibility, since it is easy to visualize multiples of one small ECG square with the aid of a magnifier. ${ }^{11-16}$

Dichotomous data were collected for the presence or absence of P-vector verticalization, IAB, and s-Ptf. The categorical data were analyzed using the chi-squared test with Yates's correction. The Pearson correlation test was used to determine correlation between the amplitude of i-PV1 and frontal P-vector and also between i-PV1 and P-amplitude in lead III. A two-sided $P$-value $<0.05$ was considered statistically significant. Statistical analyses were performed using GraphPad Prism version 6 (GraphPad Software, La Jolla, CA, USA).

\section{Results}

Mean age ( \pm standard deviation) of the study population was $65.4 \pm 10.2$ years $(n=176)$, of which $48 \%$ were males. A total of 147 patients $(83.5 \%)$ had an active or remote history of smoking. Mean ( \pm standard deviation) forced expiratory volume at 1 second of the study population was $50.2 \%( \pm 18.5)$. All patients enrolled in the investigation had a documented diagnosis of pulmonary emphysema supported by clinical history, pulmonary function test results, and radiological studies, either chest radiograph (with findings of increased radiolucency of the lungs, flat diaphragm, and a long, narrow heart shadow) or computerized tomographic scan of the chest showing emphysematous changes. Table 1 summarizes the results of P-wave indices. A total of 125 patients $(71 \%)$ had vertical $\mathrm{P}$-axis $\left(>60^{\circ}\right), 69$ patients $(39.2 \%)$ had interatrial block, and 93 patients $(52.8 \%)$ had significant $\mathrm{Ptf}$ ( $\geq 40$ mm.ms).

Figure I (A and B) Schematic illustration of how to calculate Ptf. Notes: (A) Biphasic $P$-wave in $V_{1}$. (B) Full negative $P$-wave in $V_{1}$. Abbreviation: s-Ptf, significant P-terminal force. 
Table I Incidence of IAB, s-Ptf and type of P-wave morphology in lead VI in emphysema patients based upon the presence of vertical or non-vertical P-vector

\begin{tabular}{lllll}
\hline Variable & $\begin{array}{l}\text { Vertical } \\
\text { P-axis }\left(>\mathbf{6 0}^{\circ}\right)\end{array}$ & $\begin{array}{l}\text { Nonvertical } \\
\text { P-axis }\left(\leq \mathbf{6 0}^{\circ}\right)\end{array}$ & Total (n) \\
\hline Emphysema patients & $125(71 \%)$ & $51(29 \%)$ & $176(100 \%)$ & -value \\
IAB & $45(36 \%)$ & $24(47 \%)$ & $69(39.2 \%)$ & - \\
s-Ptf & $73(58.4 \%)$ & $20(39.2 \%)$ & $93(52.8 \%)$ & 0.23 \\
P $(-) V_{1}$ & $55(71.4 \%)$ & $12(60 \%)$ & $67(65 \%)$ & 0.03 \\
P (+l-) $V_{1}$ & $18(24.6 \%)$ & $8(40 \%)$ & $26(25 \%)$ & \\
\hline
\end{tabular}

Abbreviations: s-Ptf, significant $P$-terminal force; $I A B$, interatrial block; $P(-) V_{1}$, fully negative $P$-wave in lead $V_{1} ; P(+/-) V_{1}$, biphasic $P$-wave morphology in lead $V_{1}$.

\section{Relation between significant P-terminal force and vertical $P$-vector}

A total of 73 of 125 (58.4\%) emphysema patients with vertical P-axis had s-Ptf, while only 20 of 51 (39.2\%) emphysema patients with nonvertical P-axis had s-Ptf. In other words, of 93 patients who had s-Ptf, 73 (78.5\%) had vertical P-vectors. Thus, s-Ptf was found to have a statistically significant correlation with vertical P-vectors $(P=0.03)$ (Table 1).

We also attempted to estimate the correlation of the two types of s-Ptf, viz biphasic or totally negative P-wave morphology in $\mathrm{V}_{1}$. In general, totally negative $\mathrm{P}$-waves in $\mathrm{V}_{1}$ leading to s-Ptf were more common in emphysema. Of 93 emphysema patients who had s-Ptf, 67 (72\%) had a fully negative $\mathrm{P}$-wave in $\mathrm{V}_{1}$. There was no statistically significant difference in the types of s-Ptf found in emphysema patients with either vertical or nonvertical P-vectors $(P=0.28)$ (Table 1$)$.

\section{Relation between IAB and vertical P-vector}

IAB was prevalent in 69 of $176(39.2 \%)$ emphysema patients. A total of 45 of 69 patients $(65.2 \%)$ with IAB had vertical P-vectors, whereas, 24 of 69 patients $(34.8 \%)$ with IAB had nonvertical P-vectors. The distribution pattern was not statistically significant among the two groups $(P=0.23)$ (Table 1).

\section{Relation between s-Ptf and IAB}

The overall incidence of s-Ptf was 52.8\% (93 of 176 patients), and IAB was $39.2 \%$ (69 of 176 patients) (Table 1). A total of 48 of $69(70 \%)$ patients with IAB had s-Ptf, while 61 of 107 (57\%) patients without IAB did not have s-Ptf. The association between IAB and s-Ptf was highly significant $(P=0.001)$ (Figure 2).

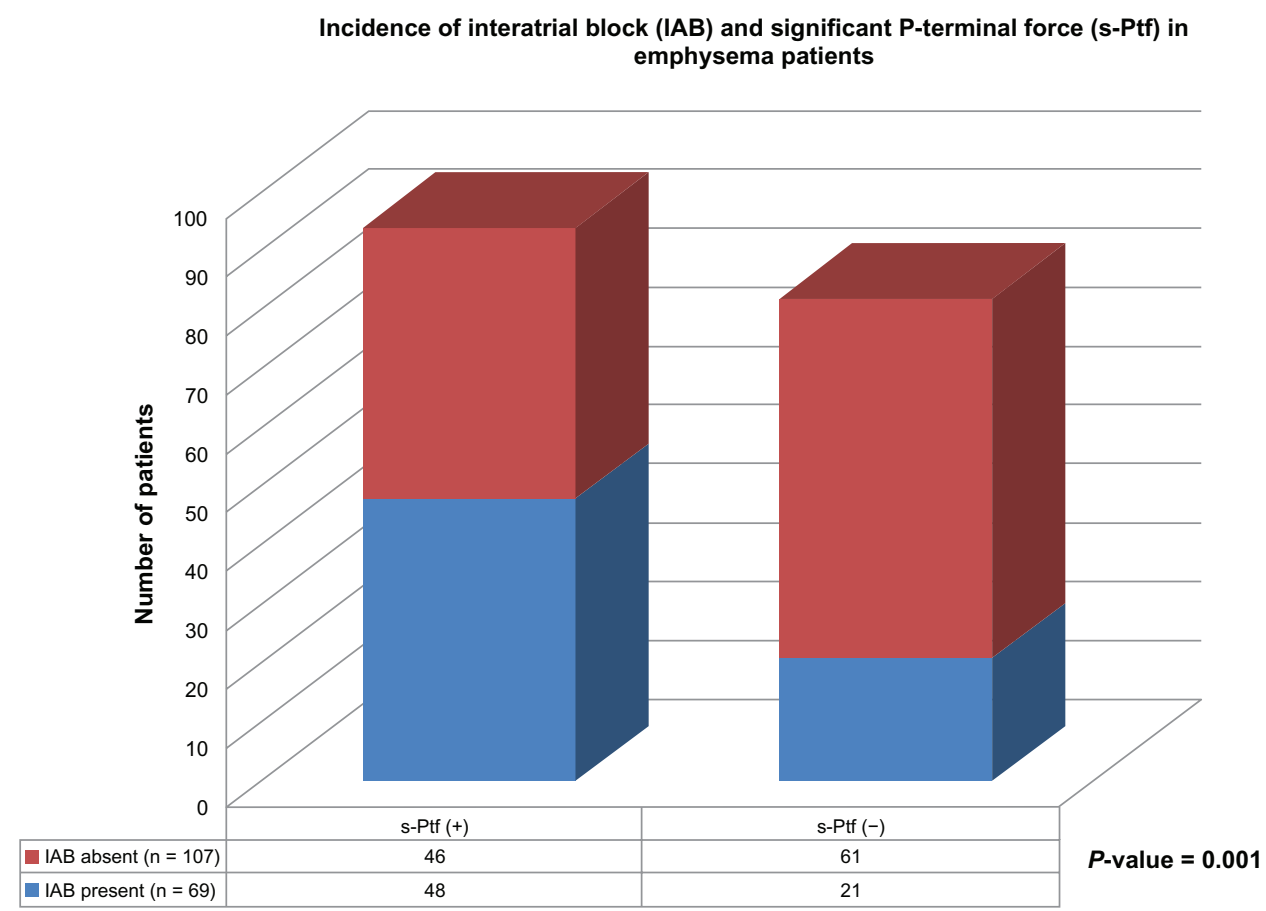

Figure 2 Schematic illustration of the incidence of interatrial block (IAB) and significant P-terminal force (s-Ptf) in emphysema patients. Abbreviations: IAB, Interatrial block; s-Ptf (+), presence of significant P-terminal force; s-Ptf (-), absence of significant P-terminal force. 
In addition, we attempted to determine if a particular type of s-Ptf (biphasic vs fully negative $\mathrm{P}$-wave in $\mathrm{V}_{1}$ ) better correlated with the presence of IAB. The results showed that fully negative $\mathrm{P}$-waves in $\mathrm{V}_{1}$ were more common in both types of patients, either with or without IAB. Neither type of P-morphology in $\mathrm{V}_{1}$ better correlated with the presence of IAB when s-Ptf was present $(P=0.7)$ (Figure 3 ).

\section{Amplitude of initial positive P-component in $\mathrm{V}$, and its relation with $\mathrm{P}$-vector}

i-PV1 $>1.5 \mathrm{~mm}$ is a known ECG sign of right atrial enlargement or right atrial strain, and was found to be prevalent in only five of 176 emphysema patients (2.8\%). All five patients who had i-PV1 $>1.5 \mathrm{~mm}$ had a vertical P-vector, while no patient with non-vertical P-vector had i-PV1 $>1.5 \mathrm{~mm}(P=0.3)$.

There was a very weak overall correlation between the degree of P-vector and magnitude of i-PV1 in all emphysema patients (Pearson correlation coefficient $r=0.15$, $P=0.047)$.

\section{Relation between i-PVI and P-amplitude in leads II and III}

Since i-PV1 and P-amplitude in leads II and III all represent right atrial abnormality, a correlation was performed among these parameters. We did not find any significant correlation between i-PV1 and P-amplitude in lead III (Pearson correlation coefficient $r=0.07, P=0.36$ ).
P-amplitude in lead II $>2.5 \mathrm{~mm}$ is called P pulmonale, and is known to reflect right atrial enlargement or right atrial abnormality. Prevalence of P pulmonale in our study was found in only $5 \%$ of emphysema patients (nine of 176 patients).

\section{Discussion}

Ptf on ECG accounts for left atrial activity, and previous studies have revealed that significant Ptf ( $\geq 40 \mathrm{~mm} . \mathrm{ms}$ ) is a highly specific sign for left atrial enlargement. ${ }^{11-13}$ IAB represents an interatrial conduction delay and often accompanies an enlarged left atrium, though it may be present in the absence of left atrial enlargement. Ptf and IAB are often together referred to as signs of left atrial abnormality. ${ }^{11-13}$ Emphysema or chronic obstructive pulmonary disease tends to cause right heart overload, in turn commonly manifesting as signs of right atrial abnormality on electrocardiogram. Conceptually, emphysema should directly exert little effect on the left atrium, except indirectly decreasing the left atrial filling rate, especially during exacerbation resulting from right heart overload. In that respect, one can project that ECG changes sometimes may transiently mimic a left atrial or rather biatrial abnormality. In our study, prevalence of IAB was around $40 \%$, which is comparable to the general prevalence of IAB in this age-group, as shown by previous studies. ${ }^{14-17} \mathrm{~s}$-Ptf and IAB showed a significant correlation in our study results, which is not very surprising, as both ECG parameters are markers of left atrial abnormality, and the

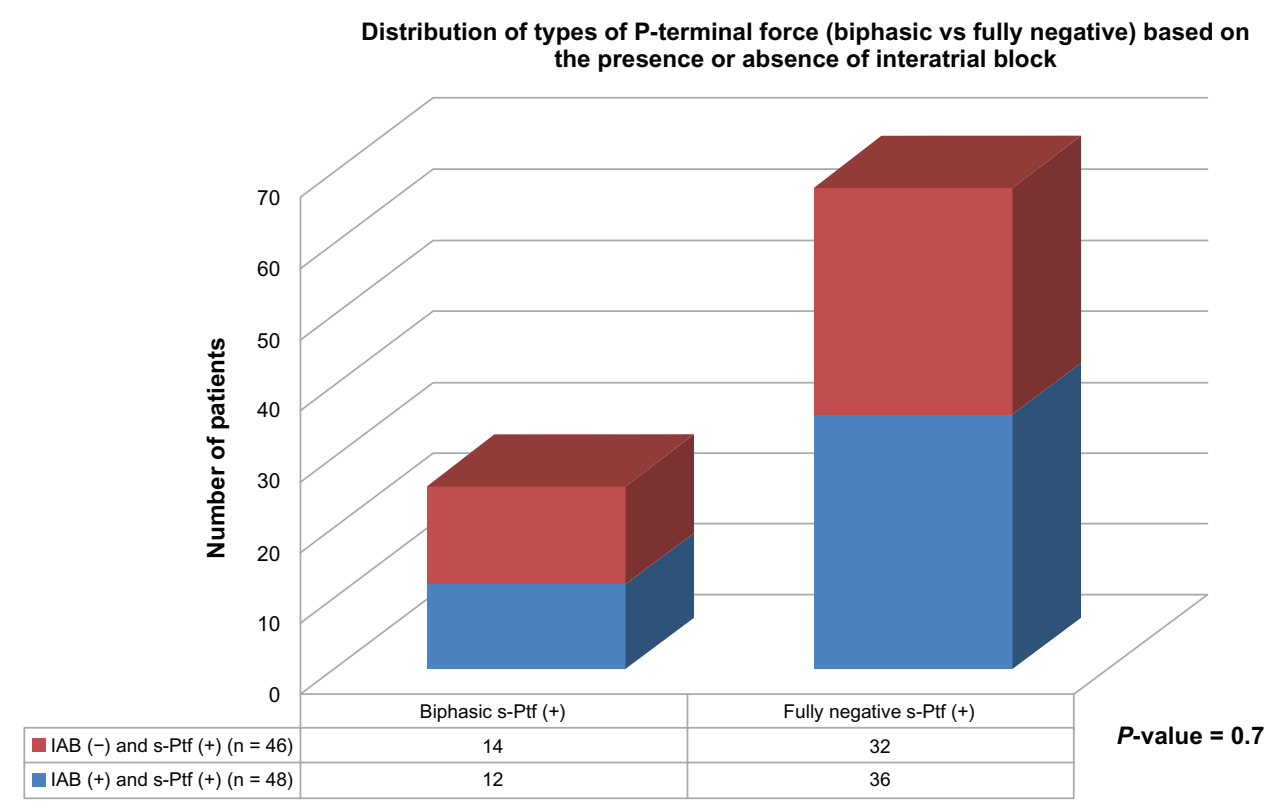

Figure 3 Distribution of types of P-terminal force (Biphasic vs. Fully negative) based on the presence or absence of interatrial block. Abbreviations: IAB, interatrial block; s-Ptf, significant P-terminal force. 
presence of one may increase the likelihood of presence of the other parameter. Previous studies including echovolumetric investigations have shown that in the presence of IAB, the left atrium is often hypocontractile. ${ }^{18}$

The results of our study clearly show that Ptf is affected by emphysema. In fact, the most commonly encountered type of s-Ptf was due to a fully negative P-wave morphology in $\mathrm{V}_{1}$ (Figure 4). These results are very interesting, and in fact quite contradictory to what one would expect in emphysema. Anatomically, the right atrium is anterior to the left atrium, and the left atrium is a posterior structure. The right atrium depolarizes toward lead $\mathrm{V}_{1}$, tending to cause an initial positive deflection, and the left atrium depolarizes later and posteriorly, tending to cause a negative P-deflection (negative $\mathrm{Ptf}$ ) in $\mathrm{V}_{1}$. One should expect an increased amplitude of i-PV1 $(>1.5 \mathrm{~mm})$ in emphysema due to right atrial enlargement/ abnormality; however, this finding was a rarity in our investigation. In addition, the incidence of totally negative $\mathrm{P}$-waves in $\mathrm{V}_{1}$ with an increased Ptf was noted more often. This finding could possibly be due to either net cancellation of right atrial potential by overwhelming left atrial forces, or it could be more likely due to positional displacement of the right atrium. In patients with emphysema, the diaphragm is flat due to lung hyperinflation, and this pulls the heart/ right atrium downwards, as the right atrium is attached to it by a dense pericardial ligament. ${ }^{1,3}$ Thus, in emphysema, although the lead placement of $\mathrm{V}_{1}$ on the chest surface may be standard, in actuality it monitors electrical forces of a much lower-situated heart (right atrium), which probably records the atrial depolarization forces going away from lead $\mathrm{V}_{1}$, resulting in a negative $\mathrm{P}$-deflection.

Our results show that $\mathrm{P}$ pulmonale and i-PV1 $>1.5 \mathrm{~mm}$ carry poor sensitivity by themselves in diagnosing emphysema, as these findings were present in only about $5 \%$ and $3 \%$ of emphysema patients, respectively. Degree of P-vector and i-PV1 carried a very weak correlation, and P-amplitude in lead III and i-PV1 similarly carried no significant correlation, which may suggest that verticalization of P-vector in emphysema might be a more functional outcome of diaphragmatic depression from severe emphysema rather than right atrial strain or right atrial enlargement. Previous studies have postulated several reasons for vertical P-vector in emphysema, like right atrial enlargement or right atrial strain from right heart overload, chronic hypoxemia, and right atrial distortion. ${ }^{5}$ Our current investigation reveals that though all these factors may potentially contribute to $\mathrm{P}$-vector verticalization in emphysema, the major role is played by right atrial/mediastinal displacement resulting from pulmonary hyperinflation. Our study results are also consistent with one of the previous echovolumetric
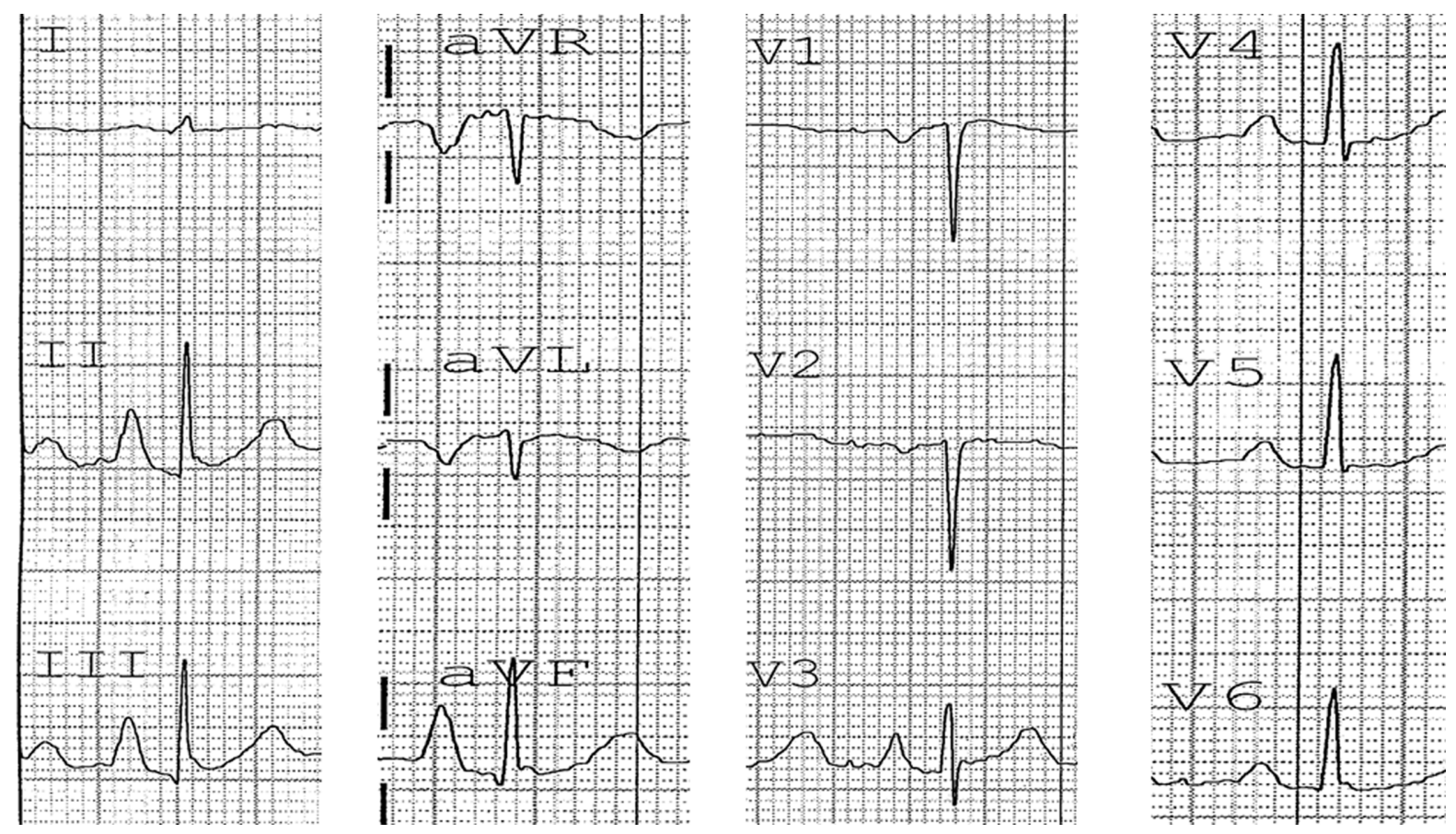

Figure 4 Electrocardiogram of a patient with emphysema.

Notes: Vertical P-vector and $\mathrm{P}$ pulmonale is present. Note the presence of a fully negative P-wave in VI with significant $\mathrm{P}$-terminal force (approximately 80 mm.ms). Based on the presence of $\mathrm{P}$ pulmonale and suspected right atrial strain/enlargement, one should expect a tall initial positive P-component in VI, which is in fact absent, suggesting primary contribution of diaphragmatic flattening and right atrial anatomical distortion to the generation of vertical P-vector. 
investigations, which found a lack of correlation between $\mathrm{P}$ pulmonale and right atrial overload in chronic obstructive pulmonary disease patients. ${ }^{20}$

\section{Limitations}

The diagnosis of emphysema was not based on high-resolution computed tomography scans in all study patients, which are known to have higher sensitivity and specificity for diagnosing structural emphysematous changes. Our investigation lacked a control group, as all patients in our study had a diagnosis of emphysema. Echocardiographic correlations were not performed for the observed ECG findings in our study.

\section{Conclusion}

s-Ptf is often present in patients with emphysema, and occurs likely as a result of the direct effects of emphysema on atrial anatomy. Vertical P-vectors in emphysema patients better correlate with s-Ptf, as compared with a nonvertical P-vectors.

Totally negative $\mathrm{P}$-waves rather than biphasic $\mathrm{P}$-wave morphology in $\mathrm{V}_{1}$ leading to s-Ptf are more common in emphysema. There was, however, no statistically significant difference in the incidence of types of s-Ptf (viz totally negative $\mathrm{P}$-wave in $\mathrm{V}_{1}$ vs. biphasic $\mathrm{P}$-wave in $\mathrm{V}_{1}$ ) in emphysema patients with either vertical or nonvertical P-vectors.

There was no significant correlation between i-PV1 and P-amplitude in lead III, suggesting that verticalization of P-vectors in emphysema might be a more functional outcome of diaphragmatic depression from severe emphysema rather than right atrial strain or right atrial enlargement.

\section{Disclosure}

The authors report no conflicts of interest in this work.

\section{References}

1. Spodick DH. Electrocardiographic studies in pulmonary disease. I. Electrocardiographic abnormalities in diffuse lung disease. Circulation. 1959;20:1067-1072.
2. Zuckerman R, Cabrera CE, Fishleder BL, Sodi-Pallares D. The electrocardiogram in chronic cor pulmonale. Am Heart J. 1948;35: 421-425.

3. Chhabra L, Sareen P, Perli D, Srinivasan I, Spodick DH. Vertical P-wave axis: the electrocardiographic synonym for pulmonary emphysema and its severity. Indian Heart J. 2012;64:40-42.

4. Spodick DH. Vectorcardiogram in pulmonary emphysema: its relation to scalar electrocardiographic findings. Am Rev Respir Dis. 1968;98: 634-639.

5. Chhabra L, Spodick DH. Transient super-Himalayan P-waves in severe pulmonary emphysema. J Electrocardiol. 2012;45:26-27.

6. Chhabra L, Sareen P, Gandagule A, Spodick DH. Visual computed tomographic scoring of emphysema and its correlation with its diagnostic electrocardiographic sign: the frontal $\mathrm{P}$ vector. $J$ Electrocardiol. 2012;45:136-140.

7. Chhabra L, Sareen P, Gandagule A, Spodick D. Computerized tomographic quantification of chronic obstructive pulmonary disease as the principal determinant of frontal P vector. Am J Cardiol. 2012;109: 1046-1049.

8. Bajaj R, Chhabra L, Basheer Z, Spodick DH. Optimal electrocardiographic limb lead set for rapid emphysema screening. Int J Chron Obstruct Pulmon Dis. 2013;8:41-44.

9. Thomas AJ, Apiyasawat S, Spodick DH. Electrocardiographic detection of emphysema. Am J Cardiol. 2011;107:1090-1092.

10. Baljepally R, Spodick DH. Electrocardiographic screening for emphysema: the frontal plane P axis. Clin Cardiol. 1999;22:226-228.

11. Chhabra L, Chaubey VK, Devadoss R, Spodick DH. Interatrial block in modern era. Curr Cardiol Rev. In press 2013.

12. Surawicz B, Knilans T. Atrial abnormalities. In: Chou's Electrocardiography in Clinical Practice: Adult and Pediatric, 6th ed. Philadelphia: Saunders Elsevier; 2008:33-36.

13. Bayés de Luna A, Platonov P, Cosico F, et al. Interatrial blocks. A separate entity from left atrial enlargement: a consensus report. J Electrocardiol. 2012;45:445-451.

14. Asad N, Spodick DH. Prevalence of interatrial block in a general hospital population. Am J Cardiol. 2003;91:609-610.

15. Jairath UC, Spodick DH. Exceptional prevalence of interatrial block in a general hospital population. Clin Cardiol. 2001;142:823-827.

16. Chhabra L, Srinivasan I, Sareen P, Anand C, Spodick DH. Interatrial block - a novel risk factor for acute mesenteric ischemia. Indian $J$ Gastroenterol. 2012;31:191-194.

17. Gialafos E, Psaltopoulou TG, et al. Prevalence of Interatrial block in young healthy men $<35$ years of age. Am J Cardiol. 2007;100: 995-997.

18. Goyal SB, Spodick DH. Electromechanical dysfunction of the left atrium associated with interatrial block. Am Heart J. 2001;142:823-827.

19. Shah NS, Koller SM, Janower ML, Spodick DH. Diaphragm levels as determinants of $\mathrm{P}$ axis in restrictive vs obstructive pulmonary disease. Chest. 1995; 107:697-700.

20. Maeda S, Katsura H, Chida K, et al. Lack of correlation between $\mathrm{P}$ pulmonale and right atrial overload in chronic obstructive airways disease. Br Heart J. 1991;65:132-136.
International Journal of COPD

\section{Publish your work in this journal}

The International Journal of COPD is an international, peer-reviewed journal of therapeutics and pharmacology focusing on concise rapid reporting of clinical studies and reviews in COPD. Special focus is given to the pathophysiological processes underlying the disease, intervention programs, patient focused education, and self management protocols.
Dovepress

This journal is indexed on PubMed Central, MedLine and CAS. The manuscript management system is completely online and includes a very quick and fair peer-review system, which is all easy to use. Visit $\mathrm{http}: / /$ www.dovepress.com/testimonials.php to read real quotes from published authors. 